\title{
Método de Cocriação de Moda Funcional para Pessoas com Deficiência
}

\author{
Method of Functional Fashion Co-creation for People with Disabilities \\ BROGIN, Bruna; Mestra; Universidade Federal do Paraná \\ brunabrogin@hotmail.com \\ OKIMOTO, Maria Lucia; Doutora; Universidade Federal do Paraná \\ lucia.demec@ufpr.br
}

\section{Resumo}

Pessoas com deficiência encontram dificuldade em vestir-se de maneira autônoma e rápida devido à falta de funcionalidade das roupas. Designers de moda por vezes carecem de conhecimento de como projetar roupas inclusivas, devido à falta de instruções sobre as deficiências e problemas na coleta de dados com os usuários. Objetiva-se desenvolver um método de cocriação de moda funcional para pessoas com deficiência a partir do levantamento bibliográfico sobre cocriação, moda e deficiência. Após a pesquisa bibliográfica desenvolveu-se o Método de Cocriação de Moda Funcional para Pessoas com Deficiência, que é estruturado em três fases principais: Pré-design, Geração e Prototipagem e Avaliação, cada fase possui seis etapas que guiam o desenvolvimento do projeto, e para cada etapa é indicada uma ferramenta a ser usada. Futuros trabalhos podem detalhar a apresentação das ferramentas e a aplicação do método.

Palavras Chave: Método de Cocriação; Moda Funcional; Pessoas com Deficiência.

\begin{abstract}
People with disabilities find difficult to dress themselves autonomously and quickly due to the lack of functionality of the clothes. There is a need of knowledge on how to collect data on people with disabilities and then design inclusive clothing. The objective is to develop a method of functional fashion co-creation for people with disabilities based on the bibliographical survey on co-creation, fashion and disability. After the bibliographic research, the Functional Fashion Co-creation Method for People with Disabilities was developed, which is structured in three main phases: Pre-design, Generation and Prototyping and Evaluation, each phase has six phases that guide the development of the project, and for each one a tool to be used is indicated. Future works can detail the presentation of the tools and the application of the method.
\end{abstract}

Keywords: Method of Co-creation; Functional Fashion; Disabled people. 


\section{Introdução}

Segundo a Organização Mundial da Saúde (OMS, 2011) as pessoas com deficiência chegam a $10 \%$ da população mundial, ou seja, entre 600 e 700 milhões de indivíduos. No Brasil, segundo o último Censo realizado pelo Instituto Brasileiro de Geografia e Estatística (IBGE, 2010), 23,9\% da população possui alguma deficiência, o que representa em torno de 45,6 milhões de pessoas. Em concordância com Brasil (2004) as pessoas com deficiência são aquelas que possuem limitações ou incapacidade para o desempenho de atividade.

Gupta (2011) define que as roupas funcionais são roupas ou modelagens especificamente construídas para entregar uma performance predefinida ou funcionalidade ao usuário, para além das suas funções básicas de cobertura do corpo, proteção e estética. Estas roupas possuem sete segmentos, um deles é chamado de "Roupas para necessidades especiais" e compreende a função de "Dar possibilidade de roupas para idosos, crianças e pessoas com deficiência" (GUPTA, 2011, p.2).

Assim, produtos de vestuário para atender as necessidades das pessoas com deficiência tem sido um desafio no campo da pesquisa científica. A Rede de Pesquisa e Desenvolvimento em Tecnologia Assistiva (RPDTA): Ações Integradas Entre Engenharia Mecânica e Design, vem desenvolvendo desde 2015, junto aos seus respectivos programas de Pós-graduação, pesquisando com foco nas pessoas com deficiência. Uma das áreas temáticas da RPDTA é "Estudos sobre os auxílios da vida prática que favoreçam o desempenho autônomo e independente em tarefas rotineiras ou facilitem o cuidado" (OKIMOTO, 2014, p.1).

Brogin, Okimoto e Martino (2017) identificaram o potencial da cocriação para moda, e a pesquisa de Brogin e Okimoto (2018) identificou que designers de moda que projetam para inclusão possuem dúvidas e incertezas durante o processo de desenvolvimento do design e prototipação, e estão dispostos a usarem um método para Ihes auxiliarem.

Em consonância com o objetivo da RPDTA e a partir das pesquisas acima citadas destaca-se a necessidade do desenvolvimento de um Método de Cocriação de Moda Funcional para Pessoas com Deficiência. Esta necessidade se ancora na quantidade de pessoas com deficiência que carecem de produtos do vestuário funcional adaptados as suas atividades da vida diária, e passíveis de proporcionar autonomia, satisfação e qualidade de vida a elas e seus cuidadores.

Objetiva-se propor um método de cocriação de moda funcional para pessoas com deficiência a partir do levantamento bibliográfico sobre o tema; bem como aprofundar o conhecimento em ferramentas que auxiliariam no processo de aplicação do método. O diferencial do método a ser proposto no decorrer deste artigo é seu ineditismo, visto que existem métodos de cocriação, métodos de cocriaçao voltados ao desenvolvimento de produtos de moda, métodos de cocriação voltados ao desenvolvimento de tecnologias assistivas, porém não existem métodos de cocriação focados no desenvolvimento de moda funcional que vise atender as demandas de pessoas com deficiência. O próximo passo seria detalhar as ferramentas e aplicar o método para avaliar sua eficácia.

\section{Método}

Segundo Gil (2002) esta pesquisa possui natureza básica, pois não visa aplicação prática do método, e sim sua discussão a nível teórico. A abordagem é qualitativa, visto que o objetivo é utilizar as informações dos artigos, e não a bibliometria quantitativa referente a pesquisa bibliográfica. 
O objetivo deste artigo é descritivo, na medida em que descreve o que a literatura aponta como métodos de cocriação, métodos de desenvolvimento de produtos de moda, e métodos de desenvolvimento de produtos de Tecnologia Assistiva (para pessoas com deficiência). Como procedimento técnico foi realizado um levantamento bibliográfico com as palavras chaves na plataforma Capes Periódicos, nas bases de dados da área de Ciências Sociais Aplicadas. As palavras selecionadas foram: cocriação, moda, deficiência, bem como seus termos correspondentes em inglês (cocriation/codesign, fashion/ clothes/garment/ apparel, impairment/ disability).

Os títulos foram pré-selecionados quando havia sintonia ao tema de pesquisa, fazendo-se na sequência a leitura do resumo. Quando haviam informações relevantes no resumo, efetuava-se o download do artigo completo para a leitura. Grande parte dos artigos selecionados será citado neste artigo nas seções que seguem. Este método foi aplicado com base nos estudos de Conforto, Amaral e Silva (2011) sobre Revisão Bibliográfica Sistemática (RBS).

Após a leitura dos artigos e extração das informações necessárias os dados foram analisados pelos autores, unindo-se ao método existente de cocriação para moda fases específicas e importantes para projetar para pessoas com deficiência, e assim desenvolveu-se uma configuração para o Método de Cocriação de Moda Funcional para Pessoas com Deficiência. A partir dos conhecimentos dos autores e da pesquisa bibliográfica realizada foram propostas ferramentas de design para aplicar em cada fase do método desenvolvido.

\section{Métodos de Cocriação, Moda e Desenvolvimento de Produtos para Pessoas com Deficiência}

Os principais trabalhos encontrados são aqui discutidos, iniciando-se pela cocriação. Segundo Yang, Kincade e Chen-Yu (2015) a cocriação, ou codesign, é um tipo de Customização em Massa que na moda é representado pela média modularidade e variedade nos tamanhos e no design dos componentes, ou módulos que formam as roupas. Isto significa que as roupas feitas a partir da cocriação proporcionam um equilíbrio entre "liberdade" ou "variedade" para os usuários escolherem aquilo que querem em suas roupas. Desta maneira estão aptos a definirem modelos, tecidos, aviamentos, tamanhos; ao passo em que, também, podem optar por módulos predefinidos pelos designers ou pela empresa. Este tipo de desenvolvimento de produtos é ideal para trabalhar com o público com deficiência, devido as particularidades corporais e psicológicas destes.

A variedade nos tamanhos, por exemplo, permite acomodar pessoas com tamanhos e dimensões corporais que fogem à regra das tabelas de medidas usadas na moda. A modularidade auxilia o usuário que não possui conhecimentos de moda, e mesmo as pessoas com deficiência intelectual, facilitando sua compreensão sobre as possibilidades de personalização, permitindo que faça uma escolha para a roupa que represente seu estilo estético e personalidade.

Piqueras (2013) apresenta o desenvolvimento de uma empresa que vende camisas virtualmente utilizando-se da cocriação. A FashionAble atendeu com sucesso pessoas com deficiência motora com diferentes habilidades, mostrando que a cocriação aplicada a moda para pessoas com deficiência é um caminho promissor.

Hussain e Sanders (2012) utilizaram ferramentas de codesign para cocriar próteses de perna com crianças Cambojanas. Muitos problemas foram enfrentados devido a fatores históricos e sociais que fizeram com que as crianças não expressem facilmente suas opiniões. Uma ferramenta aplicada 
foi a boneca de papel. As autoras perceberam que era mais fácil as crianças falarem a respeito de "uma pessoa" de que de si mesmas, e que as crianças conseguiam projetar seus desejos nas bonecas para falar de suas necessidades e receios que perpassavam o uso da prótese de perna.

Mercur (2016) em sua cartilha exemplifica seu processo de cocriação utilizado para codesenvolver produtos com pessoas com deficiência e seus familiares. A empresa que é parceira do projeto Diversidade na Rua utiliza-se de 6 fases: (a) Identificar a necessidade, (b) criação da linha de trabalho, (c) definição da problemática da linha de trabalho, (d) oficinas de cocriação, (e) oficinas de legitimação e (f) resultado. O projeto ainda está em seu início e vem se adaptando a realidade de cada grupo com o qual é aplicado, mas por meio do processo proposto catorze produtos já foram desenvolvidos e hoje estão à venda no site da empresa, pois podem atender outras pessoas com deficiência.

Segundo Sanders e Stappers (2014) (figura 1) no processo de cocriação de design existe um "prédesign", onde são estudados os contextos de experiência dos clientes e são identificadas oportunidades, e uma fase de "geração", onde são definidas as oportunidades de design, e é tomada uma decisão e estabelecida uma oportunidade de design. Nestas duas fazes complexas sondas e toolkits são ferramentas a serem empregadas a fim de captar as reações e sugestões dos usuários. $\mathrm{Na}$ fase de "avaliação" é realizado o desenvolvimento do design, a produção, e o lançamento do produto e são empregados protótipos como ferramentas que avaliam e refinam a proposta de forma iterativa. Na fase de "pós-design" é avaliado como os usuários realmente experienciam a solução.

Figura 1: O framework revisado: três abordagens para fazer estão posicionadas em relação à mentalidades e fases no processo de design.

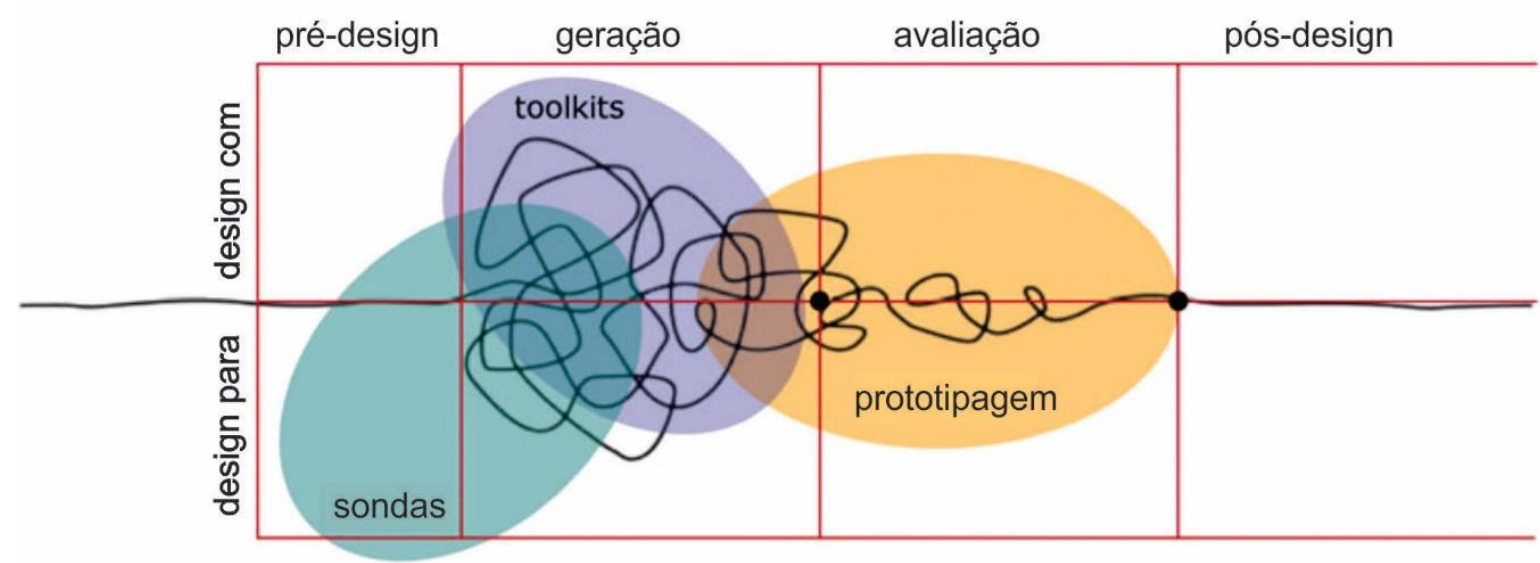

Fonte: Sanders e Stappers, 2014, p. 11, tradução das autoras.

O kit de ferramentas (toolkit) proposto pelo Human Center Design (IDEO, 2013) foi desenvolvido para auxiliar empresas que em primeiro lugar querem inovar, e o fazem atendendo mercados da base da pirâmide (com baixo poder econômico), entrando em novas regiões, adaptando tecnologias para outras regiões, entendendo mais a fundo as necessidades dos usuários, e descobrindo novos métodos de monitoramento.

A metodologia proposta pelo IDEO (2013) ancora-se em ouvir, criar e implementar. Este toolkit visa implementar os dados que as empresas possuem, facilitar a identificação de novas 
oportunidades de mercado, e aumentar a velocidade e eficácia na criação de novas soluções utilizando-se da cocriação. Além de poder ser combinada a outras ferramentas este toolkit emerge do princípio de que os usuários são especialistas, pois eles sabem o que realmente precisam (IDEO, 2013).

A aplicação de toolkits para moda já foi realizada por outros pesquisadores. Hur e Beverley (2013) partiram dos quatro níveis de criatividade descrito por Sanders (2006) (completando, adaptando, fazendo, criando), da necessidade de "espaços de design", do fornecimento de ferramentas para codesign, e da análise de iniciativas em que os clientes não participam apenas nas fases finais de design do produto, e desenvolveram o The Sustainable Fashion Bridges Ideation Toolkit. Esta ferramenta se propõe a fornecer informações que permitam a cocriação de roupa entre produtores e clientes, fornecendo conhecimento a respeito do desenvolvimento de roupas mais sustentáveis.

A ferramenta utiliza o sistema de "aprender fazendo", parte de provocações que fazem o usuário refletir a respeito do tema "sustentabilidade" e se estrutura em seis temas centrais: (a) escolha, (b) otimização, (c) empoderamento, (d) persuasão, (e) interação, e (f) conversação social. The Sustainable Fashion Bridges Ideation Toolkit pode ser usado por designers de moda e têxteis, por usuários com muito ou pouco conhecimento de moda, bem como por consumidores que querem fazer escolhas de compra de roupas mais sustentáveis. Ela é utilizada individualmente ou em grupo, e auxilia na cocriação do produto de moda.

Além dos exemplos já apresentados sobre métodos de cocriação aplicados a moda e a pessoas com deficiência, Hur, Beverley e Cassidy (2013) apresentam um método voltado a cocriação de produtos de moda baseado em três estágios do design participativo proposto por Spinuzzi (2005). Este processo de desenvolvimento do design com a cocriação de moda é composto de seis fases: (a) identificação do problema, (b) análise do problema, (c) geração de ideias e pesquisa de alternativas, (d) seleção de soluções, (e) implementação e (f) prototipagem e avaliação do design, conforme figura 2 .

Figura 2 - Processo de desenvolvimento de codesign de moda

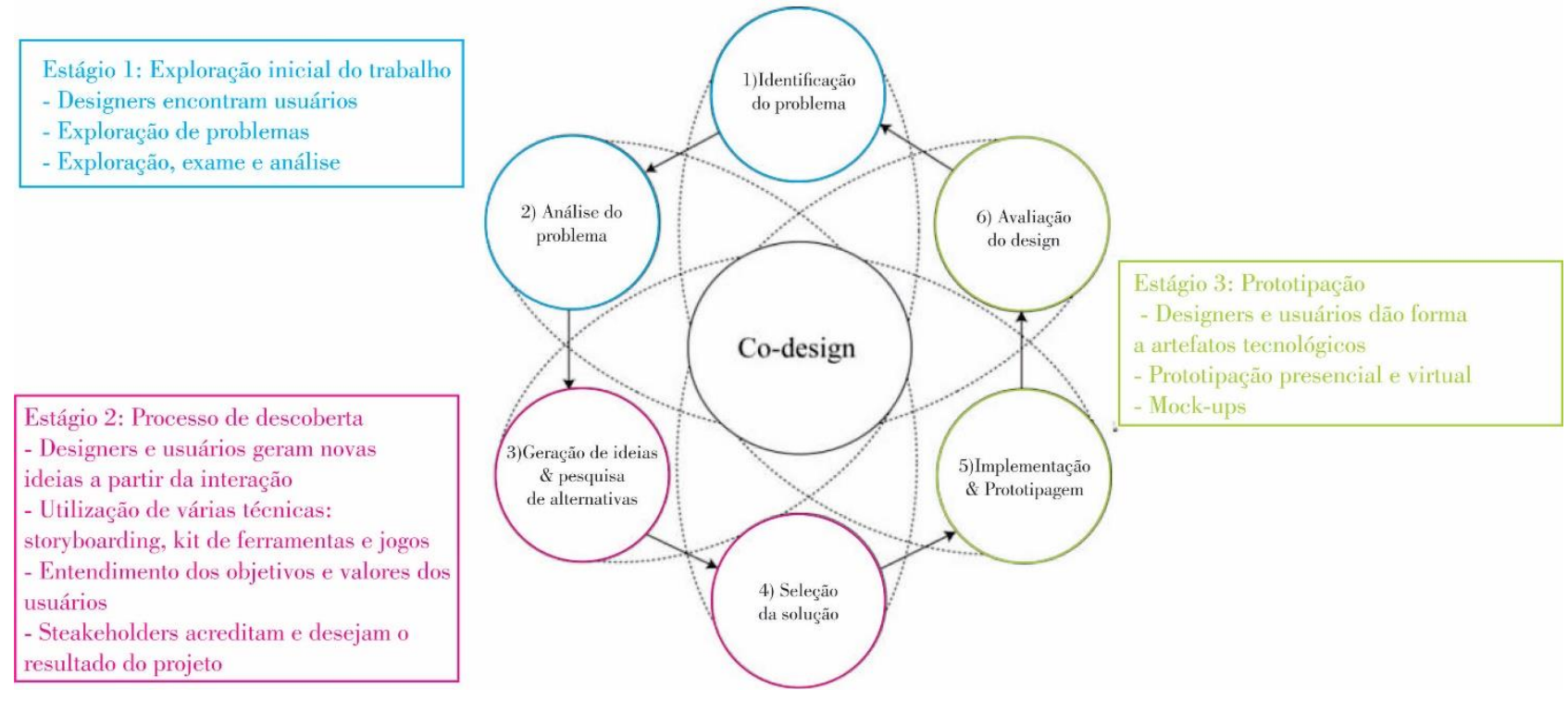


Fonte: Hur, Beverley e Cassidy, 2013, p. 93, tradução das autoras.

As etapas apresentadas no método de criação para moda de Hur, Beverley e Cassidy (2013) vem ao encontro do Método para o desenvolvimento de produtos de moda de Burns, Mullet e Bryant (2011), que destacam oito (8) passos no processo de design para os negócios de moda: (a) Pesquisa e Merchandising, (b) Design, (c) Desenvolvimento do design e seleção do estilo, (d) Marketing da linha do vestuário, (e) Pré-produção, (f) Abastecimento, (g) Processos de produção de vestuário, gestão de materiais e garantia de qualidade, e (h) Distribuição e venda.

Os três primeiros passos sugeridos pelos autores estão alinhados a fase de pesquisa e desenvolvimento de produtos de moda, e se subdividem em outras atividades que são realizadas em cada um destes momentos. O primeiro passo possui dois tipos principais de pesquisa: pesquisa de mercado e de moda. A pesquisa de mercado engloba a pesquisa com consumidor, de produto, análise de mercado, e perfil de público alvo. A pesquisa de moda engloba a pesquisa de tendência, de cor, de tecidos e aviamentos, todos alinhados com a sazonalidade e planejamento de linha.

A fase de design contempla a inspiração, planejamento da linha, seleção e desenvolvimento de tecidos e aviamentos, desenho de esboços e obtenção de amostras de fornecedores, revisão e seleção de estilos para desenvolver a linha, escrita dos papeis de especificações das roupas, e custos rápidos.

A fase de Desenvolvimento do Design engloba a realização da primeira modelagem, cortar e costurar o protótipo, aprovar o tamanho do protótipo, revisar o estilo ou alterar o estilo, estimar custos iniciais, apresentar e revisar a linha, determinação dos custos finais, ordenar mostruário para representantes, e ordenar insumos para fabricação dos mostruários. As outras etapas deste método dizem respeito ao marketing e ao planejamento da produção, não sendo alvos desta pesquisa.

Deve-se salientar a pesquisa sobre o desenvolvimento de produtos para pessoas com deficiência, destacou-se o trabalho de Maia e Freitas (2014), que propuseram um Método para o Desenvolvimento de Recursos de Tecnologia Assistiva Baseado no Ergodesign. Para os autores a Tecnologia Assistiva é entendida como "qualquer item, peça de equipamento, ou sistema de produto, adquirido comercialmente ou customizado, que é usado para aumentar, manter ou melhorar as capacidades funcionais de indivíduos com deficiência" (ASSISTIVE TECHNOLOGY ACT, 1998, 29 U.S.C. § 3001, tradução dos autores).

O método proposto por Maia e Freitas (2014) se ancora em 9 etapas para o desenvolvimento de produtos. Alguns pontos chaves deste método são área comum de métodos de desenvolvimento de produtos, por isso destaca-se aqui aqueles que chamam atenção quanto ao tratamento do usuário com algum tipo de deficiência. A relevância deste material se dá devido a ser uma abordagem da Terapia Ocupacional, muito voltada a um sujeito com características particulares.

Na etapa 1, Problematização, Maia e Freitas (2014) incluem a avaliação física, cognitiva, déficits, potenciais, observação das necessidades, verificação dos desejos, análise macro, avaliação da tarefa, análise operacional, diagnóstico e recomendações ergonômicas. Segue-se a etapa 2 , Levantamento de dados, etapa 3, Análise de Dados, e etapa 4, Projetação do Produto, onde os autores englobam as possibilidades de relação do sujeito com o produto por meio do projeto ergonômico. Na etapa 5, Avaliação e Validação do Produto, são propostos testes ergonômicos.

As etapas 6, 7 e 8 do fluxograma de Maia e Freitas (2014) dizem respeito ao Detalhamento 
do Projeto, Planejamento da Produção e Produção do Produto, respectivamente, não sendo aplicados ao método que se pretende desenvolver. A etapa 9, Avaliação da Usabilidade, se refere a testes com usuários, que validam o produto desenvolvido em seu contexto de uso, sendo importante ao método a ser apresentado.

Tais momentos no desenvolvimento de produtos de moda podem parecer exageradas, mas em se tratando de moda funcional e da cocriação tornam-se pertinentes, devido a necessidade de deixar claro para todos os cocriadores as reais necessidades do usuário, e todas as possibilidades de soluções disponíveis para o desenvolvimento do produto.

Por fim vale ressaltar que o Conselho de Design da Noruega (2010) propõe um diagrama de desenvolvimento de produtos para pessoa com deficiência que se ancora me quatro etapas, cada uma com duas atividades: (1) Explorar - entender o contexto e pesquisar o design; (2) Focar descobrir as necessidades e mapear os insights; (3) Desenvolver - traduzir instruções e construir cenários; e (4) Entregar - Feedback de usuários e construção dos recursos.

O quadro 1 apresenta a relação das fases dos principais métodos, esquemas, diagramas, fluxogramas e toolkits discutidos neste capítulo com relação a cocriação, ao desenvolvimento de produtos de moda, e ao desenvolvimento de produtos para pessoas com deficiência, deixando visível como cada autor contribui para o desenvolvimento de um método que abrange estas três áreas.

Quadro 1: Contribuição dos autores de cocriação, desenvolvimento de produtos de moda, e desenvolvimento de produtos para pessoas com deficiência, para o método que será desenvolvido.

\begin{tabular}{|c|c|c|c|c|c|}
\hline $\begin{array}{l}\text { Etapas da } \\
\text { cocriação } \\
\text { (Sanders e } \\
\text { Stappers, } \\
\text { 2014) }\end{array}$ & $\begin{array}{l}\text { Etapas da } \\
\text { cocriação } \\
\text { (IDEO, 2013) }\end{array}$ & $\begin{array}{l}\text { Etapas da } \\
\text { cocriação de } \\
\text { moda (Hur, } \\
\text { Beverley e } \\
\text { Cassidy, 2013) }\end{array}$ & $\begin{array}{l}\text { Etapas do } \\
\text { desenvolvimento } \\
\text { de produtos de } \\
\text { moda (Burns, } \\
\text { Mullet e Bryant, } \\
\text { 2011) }\end{array}$ & $\begin{array}{l}\text { Etapas do } \\
\text { desenvolvimento } \\
\text { de produtos de } \\
\text { tecnologia } \\
\text { assistiva (Maia e } \\
\text { Freitas, 2014) }\end{array}$ & $\begin{array}{l}\text { Etapas para o } \\
\text { desenvolvimento } \\
\text { de produtos } \\
\text { inclusivos } \\
\text { (Conselho de } \\
\text { Design da } \\
\text { Noruega, 2010) }\end{array}$ \\
\hline Pré-design & Ouvir & $\begin{array}{l}\text { Identificação do } \\
\text { problema } \\
\text { Análise do } \\
\text { problema }\end{array}$ & $\begin{array}{l}\text { Pesquisa e } \\
\text { Merchandising }\end{array}$ & $\begin{array}{l}\text { Problematização } \\
\text { Levantamento de } \\
\text { Dados } \\
\text { Análise de dados }\end{array}$ & $\begin{array}{l}\text { Explorar } \\
\text { Focar }\end{array}$ \\
\hline Geração & Criar & $\begin{array}{l}\text { Geração de } \\
\text { ideias e pesquisa } \\
\text { de alternativas } \\
\text { Seleção de } \\
\text { soluções }\end{array}$ & Design & $\begin{array}{l}\text { Projetação do } \\
\text { Produto }\end{array}$ & Desenvolver \\
\hline Avaliação & Implementar & $\begin{array}{l}\text { Implementação } \\
\text { Prototipagem e } \\
\text { avaliação }\end{array}$ & $\begin{array}{l}\text { Desenvolvimento } \\
\text { do Design }\end{array}$ & $\begin{array}{l}\text { Avaliação e } \\
\text { Validação do } \\
\text { Produto }\end{array}$ & Entregar \\
\hline $\begin{array}{l}\text { Pós- design } \\
\text { (avaliação da } \\
\text { experiência) }\end{array}$ & -- & -- & -- & $\begin{array}{l}\text { Avaliação da } \\
\text { Usabilidade }\end{array}$ & -- \\
\hline
\end{tabular}

Fonte: Das autoras.

\section{O Método de Cocriação de Moda Funcional para Pessoas com Deficiência}


A pesquisa bibliográfica apresentou alguns métodos para a cocriação, tanto especificamente sobre "moda", quanto para o desenvolvimento de produtos para pessoas com deficiência. Todos salientam a importância de uma primeira fase de exploração das necessidades dos usuários (Prédesign), uma fase de pesquisa de design, e geração e avaliação de alternativas, além de decisão entre uma delas (Geração), e por fim uma fase para prototipagem e avaliação do protótipo (Prototipagem e Avaliação).

O processo de cocriação apresentado por Sanders e Stappers (2014) possui quatro fases, porém as autoras acreditam que a fase de Pós-design (avaliação da experiência no usuário no contexto de uso) prolonga o processo de cocriação, principalmente quando se trata de projetos acadêmicos (possíveis usuários do método), e também por tratar-se de produtos de moda, que possuem uma rápida adoção ao uso e descarte, devido ao sistema de moda existente (BURNS, MULLET, BRYANT, 2011). Desta maneira adotou-se apenas a Avaliação da Usabilidade e Ergonomia proposta por Maia e Freitas (2014), colocando-a na fase de Avaliação. Assim, o Método proposto possui três fases: Prédesign, Geração, e Prototipagem e Avaliação.

A partir das pesquisas apresentadas no quadro 1 realizou-se a seleção daquelas fundamentais para cocriação, moda e para os projetos para o público com deficiência, elaborou-se seis etapas para cada fase proposta, conforme segue na figura 3: Método de Cocriação de Moda Funcional para Pessoas com Deficiência.

Figura 3 - Método de Cocriação de Moda Funcional para Pessoas com Deficiência

1- Definição do público alvo

2- Detalhamento do problema

3- Avaliações de saúde

4- Definição de necessidades e desejos

5- Pesquisa de produtos

6- Análise e diagnóstico da fase 1

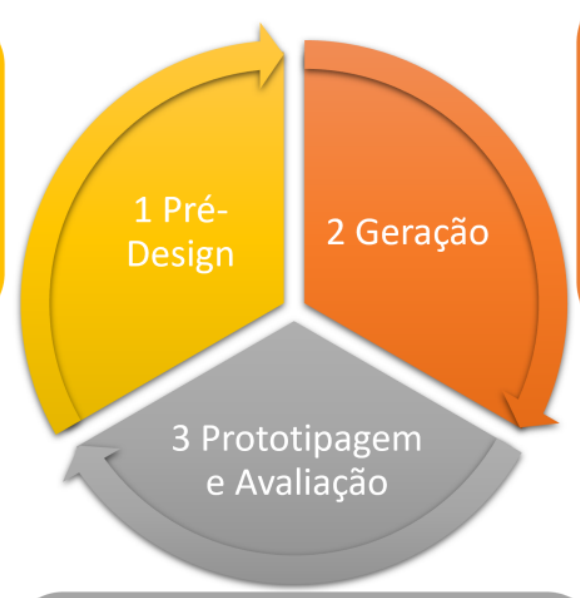

7- Planejamento da coleção 8- Pesquisa e seleção de tendências e insumos de moda 9- Ideação

10- Geração e avaliação de alternativas 11- Revisão dos modelos e da sequência 12- Preparação de documentos técnicos
13- Modelagem
14- Corte
15- Costura do protótipo
16- Aprovar ou alterar o tamanho do protótipo e estilo
17- Avaliação de usabilidade e ergonômica
18- Alterações no produto ou aprovação

Fonte: Das autoras

A primeira etapa da fase 1, Definição do Público Alvo, é embasada em todos os autores citados no quadro 1 , mas principalmente embasada no desenvolvimento de produtos de moda colocado por Burns, Mullet e Bryant (2011), visto que a primeira etapa para o desenvolvimento de 
produtos de moda é estabelecer o perfil do público que irá utilizar as roupas desenvolvidas: gênero, faixa de idade, média de renda, estilo de vida, hábitos de compra, localização geográfica, e faixa de preço de consumo de produtos.

Segundo Burns, Mullet e Bryant (2011) a definição deste grupo baseia-se no posicionamento da marca, ou seja, desenvolver os produtos certos e no tempo correto para um dado público escolhido. Para facilitar o trabalho da equipe de design estes autores sugerem o desenvolvimento de um Painel de Público Alvo, ou seja, uma colagem de imagens que represente o público escolhido. Treptow (2013) acrescenta a necessidade de pesquisar o comportamento deste público-alvo, ou seja, interesses atuais, lugares que frequenta, ídolos da música, cinema, televisão, e temas de interesse.

Pazmino (2015) apresenta, ainda, outra ferramenta muito utilizada pelos designers para facilitar o correto entendimento do público-alvo pelo time de design, o desenvolvimento de Personas, ou seja, é estipulado um nome, gênero, perfil, e todas as características para um usuário fictício das peças. O Conselho de Design da Noruega (2010) estimula que a Persona, ou Público-Alvo, seja embasado em usuários líderes, que segundo eles são pessoas com grande dificuldade em realizar determinada tarefa. Segundo estes autores quando um produto é desenvolvido para ser acessível e eficaz para pessoas com grandes limitações, consequentemente favorece aqueles com menos dificuldades.

Sanders e Stappers (2014) ao argumentar sobre as ferramentas que podem ser utilizadas em cada fase (figura 1) deixam clara a utilização de sondas para esta fase inicial de Pré-design. Segundo o Dicionário de Cambridge (2018) estas ferramentas de sondas servem para: "tentar descobrir informações que outras pessoas não querem que você saiba, fazendo perguntas com cuidado e não diretamente", e ainda "examinar algo com uma ferramenta, especialmente para encontrar algo oculto".

A partir destas colocações as autoras deste artigo pensam que um questionário semiestruturado para coletar informações pessoais, informações de roupas de uso diário e de preferências para o vestuário seria a ferramenta ideal para esta etapa. Este questionário pode ter questões norteadoras básicas e ser adaptado a cada caso de aplicação do método: utilização para o desenvolvimento de amplas coleções para um público alvo, desenvolvimento de peças sob medida para usuários únicos, desenvolvimento de minicoleções no caso de coleções cápsula, projetos universitários ou concursos de moda.

Este questionário pode ser utilizado ainda na etapa 2, Detalhamento do Problema, a fim de identificar quais as dificuldades enfrentadas por usuários e seus cuidadores com relação ao vestuário, bem como na etapa 3, Avaliações de Saúde, coletando dados sobre avaliações físicas, cognitivas, identificar déficits e potenciais dos usuários. Nesta etapa a utilização de Questionários de Qualidade de Vida podem auxiliar o projeto. Na área da saúde estes questionários são aplicados por médicos, fisioterapeutas, terapeutas ocupacionais, entre outros, a fim de avaliar a recuperação de um paciente com determinada terapia. Quando um destes profissionais participa da cocriação pode aplicar o teste, ou trazer um teste anteriormente aplicado com um usuário específico (caso de roupas personalizadas), revelando como a roupa pode melhor adaptar-se as habilidades do sujeito ou público em questão. $O$ modelo para este questionário pode ser aquele apresentado por Whithers (2014).

A etapa 2 é sugerida por todos os autores citados na quadro 1, que salientam a importância 
de detalhar o problema, Maia e Freitas (2014) especificam particularmente a necessidade de avaliações de saúde, que são propostas na etapa 3. São sugeridas: análise macro, avaliação da tarefa, análise operacional, diagnóstico ergonômico, e recomendações ergonômicas. As autoras deste artigo acreditam que nem tudo se aplica ao produto de moda, mas um ou outro teste são interessantes e podem contribuir para o desenvolvimento de peças funcionais, como por exemplo a avaliação da tarefa de vestir, realizar determinada atividade com a roupa, e despir-se. Pazmino (2015) detalha os procedimentos para esta avaliação e sua importância para os designers. Após esta avaliação podem ser realizadas recomendações para o desenvolvimento de peças específicas de roupas (como para calças, blusas, casacos, entre outros) para pessoas com determinada deficiência ou para usuários específicos.

A etapa 4, Definição de Necessidade e Desejos, se refere a coleta das funções de uso da roupa e do que os usuários gostariam que ela tivesse e de como ela se comportasse. É salientada principalmente pelos autores da área de moda, que percebem para além das necessidades o desejo de consumo de determinada peça devido ao seu valor simbólico. A etapa 5, Pesquisa de Produtos, se refere a pesquisa de produtos similares e concorrentes, de modo que se possa avaliar as soluções já existentes para desenvolver produtos com funcionalidade. Pazmino (2015) descreve como devem ser feitas estas pesquisas, e Brogin, Okimoto e Martino (2017) apresentam uma lista de empresas de moda inclusivas que podem ser o ponto de partida para as pesquisas a serem desenvolvidas pelos usuários do método.

A etapa 6, Análise e Diagnóstico, resume e prioriza os dados coletados na fase 1 , conclusão da coleta de dados realizada nas etapas anteriores, identificando quais as prioridades para modelos, tecidos, aviamentos e requisitos ergonômicos e de usabilidade que os usuários assinalaram por meio das ferramentas até então apresentadas, sendo o ponto de partida para fase subsequente.

A fase 2, Geração, inicia-se com a etapa 7, Planejamento da Coleção, etapa destacada por Burns, Mullet e Bryant (2011), bem como todas as outras etapas desta fase. No planejamento são definidas quantas peças terá a coleção, quais os segmentos atendidos, quantas superiores e inferiores, quantos itens fashion, clássicos e básicos, entre outros itens de planejamento de coleção de moda.

A etapa 8, Pesquisa e Seleção de Tendências e Insumos de Moda, são realizadas pesquisas de tendências, tecidos, cores, formas, aviamentos, tecnologias, modelos e elementos de estilo, é estabelecida uma inspiração, e a partir dela um tema de coleção, expresso por meio de um painel e um texto. Com o tema estabelecido o designer seleciona tecidos, aviamentos, cores, estampas, e cria cartelas informacionais para cada um destes elementos. A etapa 9, Ideação, é ressaltada por todos os autores do quadro 1, e neste momento de quebrar o gelo e conversar com os cocriadores de maneira criativa propõe-se discutir modelos com base em fotos de peças de roupas da moda pré-selecionadas, desenhos técnicos de módulos de roupas e fotos de roupas inclusivas e funcionais.

Na etapa 10, Geração e Avaliação de Alternativas, serão desenvolvidas alternativas de peças e combinações que atendam aos requisitos de projeto juntamente com os participantes da cocriação, bem como avaliadas as alternativas e escolhidas as melhores a fim de atender os requisitos de projeto. Para realização desta fase sugere-se o desenvolvimento de um croqui que represente o público alvo, bem como a utilização de um protocolo para definição dos modelos, onde cada um seja pontuado por critérios pré-estabelecidos nas etapas 6 e 7, fazendo que a escolha atenda aos requisitos de projeto, aos objetivos funcionais e estéticos do projeto, sendo coerente 
com os objetivos de uma cocriação.

Na etapa 11, Revisão dos Modelos e da Sequência de Looks, sugere-se rever a coerência entre os looks em relação a harmonia entre eles, elo de ligação, presença de elementos e princípios de design e estilo, conforme proposto por Treptow (2013), e caso necessários ajustes podem ser feitos nos desenhos. Um protocolo para análise da sequência de looks é sugerido pelas autoras. Na etapa 12, Preparação de Documento Técnicos, sugere-se o desenvolvimento das fichas técnicas e ordens de compra dos insumos mínimos para geração dos protótipos.

A fase 3, Prototipagem e Avaliação, é sugerida por todos os autores citados no quadro 1. Na etapa 13, Modelagem, um protocolo para coleta de medidas antropométrica para moda é indicado, pois com as peças definidas é o momento de coletar medidas corporais de usuários, caso sejam roupas feitas sob medida, ou decidir quais tabelas serão utilizadas, e qual a grade de tamanhos de interesse. Mesmo que a coleta de medidas pudesse ser realizada anteriormente ela se mostra interessante neste momento para que sejam coletadas apenas as medidas de interesse para as peças que serão desenvolvidas, diminuindo possíveis constrangimentos proveniente da coleta destas medidas.

Na sequência é desenvolvida a modelagem em papel, Moulage ou por meio de CAD. Sugerese o desenvolvimento e teste das bases nos usuários quando se tratar de peças sob medida. $\mathrm{Na}$ etapa 14 é realizado o corte das peças em tecido, e na etapa 15 a costura das peças no maquinário apropriado, bem como toda finalização necessária e descrita na ficha-técnica. Para etapa 16, Aprovar ou Alterar o Tamanho do Protótipo e Estilo, é sugerido um protocolo que avalie cada um dos requisitos de projeto estabelecidos na etapa 6, 7 e 12.

$\mathrm{Na}$ etapa 17, Avaliação de Usabilidade e Ergonômica, é sugerido que um modelo experimente a roupa e realize, com ela, atividades corriqueiras, depois, despindo-se. Salienta-se a importância de que a roupa cumpra os critérios de funcionalidade, eficiência, eficácia, satisfação, conforto e ergonomia, todos indicados por Martins (2005) no protocolo de avaliação sugerido. Na etapa 18, Alterações no Produto ou Aprovação, caso o produto não seja aprovado realiza-se um retrabalho para a peça reprovada pelo usuário no teste, caso seja aprovada segue para produção. Os detalhes de cada fase, etapa e as ferramentas estão descritas no quadro 2.

Quadro 2: Etapas, fases e ferramentas do Método de Cocriação de Moda Funcional para Pessoas com Deficiência

\begin{tabular}{lll}
\hline \multicolumn{3}{c}{ Método de Cocriação de Moda Funcional para Pessoas com Deficiência } \\
\hline & \multicolumn{1}{c}{ Fase 1- Pré-Design (design para o usuário): } \\
\hline Etapa: & Descrição: & Ferramentas: \\
\hline $\begin{array}{l}\text { 1- Definição do } \\
\text { público alvo }\end{array}$ & $\begin{array}{l}\text { Definir um público alvo ou uma pessoa a partir da percepção } \\
\text { de que precisam de funcionalidade no vestir para realizar } \\
\text { determinadas atividades, para alcançar autonomia na tarefa, } \\
\text { para vestir-se em tempo hábil, para obter melhora na saúde, }\end{array}$ & $\begin{array}{l}\text { * Desenvolver Painel de Público } \\
\text { * Utilização de Personas }\end{array}$ \\
& $\begin{array}{l}\text { entre outros. Estabelecer gênero, idade, classificações de } \\
\text { deficiência, faixa econômica... }\end{array}$ & \\
\hline $\begin{array}{l}\text { 2-Detalhamento } \\
\text { do problema }\end{array}$ & $\begin{array}{l}\text { Identificar quais as dificuldades enfrentadas por usuários e } \\
\text { seus cuidadores. }\end{array}$ & *Questionário de coleta de \\
3-Avaliações de & $\begin{array}{l}\text { Coletar dados sobre avaliações físicas, cognitivas, identificar } \\
\text { déficits e potenciais dos usuários. }\end{array}$ & $\begin{array}{l}\text { *Questionário de coleta de } \\
\text { roupas de uso diário }\end{array}$ \\
\hline
\end{tabular}




\begin{tabular}{|c|c|c|}
\hline & & $\begin{array}{l}\text { roupas de uso diário } \\
\text { *Questionário de qualidade de } \\
\text { vida } \\
\text { *Avaliação da tarefa de vestir } \\
\end{array}$ \\
\hline $\begin{array}{l}\text { 4-Definição de } \\
\text { desejos }\end{array}$ & $\begin{array}{l}\text { Coletar dados referentes as dificuldades encontradas no } \\
\text { vestir, bem como questões estéticas e de tamanho, } \\
\text { estabelecendo as necessidades a serem melhoradas no } \\
\text { projeto e os desejos dos usuários. MEDIDAS- ANÁLISE } \\
\text { ANTROPOMÉTRICA para saber os desafios em modelagem }\end{array}$ & $\begin{array}{l}\text { *Questionário de coleta de } \\
\text { informações pessoais e de } \\
\text { roupas de uso diário }\end{array}$ \\
\hline $\begin{array}{l}\text { 5-Pesquisa de } \\
\text { produtos }\end{array}$ & $\begin{array}{l}\text { Identificar os produtos disponíveis no mercado que atendam } \\
\text { o público-alvo para solução dos problemas identificados. }\end{array}$ & $\begin{array}{l}\text { *Identificar empresas que } \\
\text { produzem moda para o público } \\
\text { com deficiência e realizar } \\
\text { análise sincrônica e diacrônica }\end{array}$ \\
\hline $\begin{array}{l}\text { 6-Análise e } \\
\text { diagnóstico }\end{array}$ & $\begin{array}{l}\text { Analisar os dados coletados e estabelecer prioridades junto } \\
\text { com os usuários. }\end{array}$ & $\begin{array}{l}\text { *Protocolo de análise e } \\
\text { diagnóstico }\end{array}$ \\
\hline \multicolumn{3}{|c|}{ Fase2- Geração (design com o usuário): } \\
\hline Etapa: & Descrição: & Ferramenta: \\
\hline $\begin{array}{l}\text { 7-Planejamento } \\
\text { da coleção }\end{array}$ & $\begin{array}{l}\text { Decidir quantos looks terão na coleção, quantas peças } \\
\text { superiores e inferiores, quantos itens fashion, quantos } \\
\text { básicos, quantos clássicos, todas as subfunções que precisam } \\
\text { atender, entre outros requisitos de projeto. }\end{array}$ & $\begin{array}{l}\text { *Protocolo de metas da fase de } \\
\text { geração }\end{array}$ \\
\hline $\begin{array}{l}\text { 8-Pesquisa e } \\
\text { seleção de } \\
\text { tendências e } \\
\text { insumos de } \\
\text { moda }\end{array}$ & $\begin{array}{l}\text { Pesquisa de tendências em birôs de estilos, revistas de moda, } \\
\text { e sites de marcas conceituadas, definindo conceito e tema de } \\
\text { coleção. Visita a feiras do setor têxtil e de moda, conferir } \\
\text { catálogos de fornecedores e verificar cores, tecidos e } \\
\text { aviamentos que estão na moda e estarão disponíveis para } \\
\text { coleção. Escolher cores, tecidos e aviamentos para coleção, já } \\
\text { direcionando aqueles que apresentam acessibilidade aos } \\
\text { usuários. }\end{array}$ & $\begin{array}{l}\text { *Desenvolver Painel Conceitual } \\
\text { e texto de tema de coleção } \\
\text { *Definição de cartela de cores, } \\
\text { tecidos e aviamentos }\end{array}$ \\
\hline 9-Ideação & $\begin{array}{l}\text { Inspirando-se nas etapas anteriores e discutindo } \\
\text { possibilidade com os participantes da cocriação para deixar a } \\
\text { criatividade livre. Discutir os modelos a serem criados por } \\
\text { meio de fotos de roupas existentes (inclusivas ou não) e } \\
\text { desenhos técnicos de módulos de roupas. }\end{array}$ & $\begin{array}{l}\text { *Ferramenta para quebrar o } \\
\text { gelo e soltar a criatividade - } \\
\text { fotos de roupas existentes } \\
\text { (inclusivas ou não), desenhos } \\
\text { técnicos de módulos de roupas. }\end{array}$ \\
\hline $\begin{array}{l}\text { 10-Geração e } \\
\text { avaliação de } \\
\text { alternativas }\end{array}$ & $\begin{array}{l}\text { Gerar alternativas de peças e combinações que atendam aos } \\
\text { requisitos de projeto juntamente com os participantes da } \\
\text { cocriação, bem como avaliar as alternativas e escolher as } \\
\text { melhores a fim de atender os requisitos de projeto. }\end{array}$ & $\begin{array}{l}\text { * Desenhar soluções a partir } \\
\text { das discussões com os } \\
\text { participantes da cocriação por } \\
\text { meio um croqui pré-elaborado } \\
\text { que represente o público-alvo } \\
\text { * Protocolo para definição dos } \\
\text { modelos }\end{array}$ \\
\hline $\begin{array}{l}\text { 11-Revisão dos } \\
\text { modelos e da } \\
\text { sequência de } \\
\text { looks }\end{array}$ & $\begin{array}{l}\text { Detalhar os desenhos e fazer as alterações devidas a partir de } \\
\text { discussões com os participantes. Analisar a sequência dos } \\
\text { looks e verificar se existe coerência entre eles. }\end{array}$ & $\begin{array}{l}\text { *Se necessário fazer alterações } \\
\text { nos desenhos } \\
\text { *Protocolo para análise da } \\
\text { sequência de looks }\end{array}$ \\
\hline $\begin{array}{l}\text { 12-Preparação } \\
\text { de documentos } \\
\text { técnicos }\end{array}$ & $\begin{array}{l}\text { Desenvolvimento de ficha técnica e se necessário ordens de } \\
\text { compra. }\end{array}$ & * Ficha Técnica de Moda \\
\hline \multicolumn{3}{|c|}{ Fase 3 - Avaliação (design com e para o usuário): } \\
\hline Etapa: & Descrição: & Ferramenta: \\
\hline 13-Modelagem & $\begin{array}{l}\text { Coletar medidas antropométrica para produtos sob medida } \\
\text { ou escolher tabela de medidas para produção industrial. } \\
\text { Desenvolvimento da modelagem plana, ou Moulage em }\end{array}$ & $\begin{array}{l}\text { *Protocolo para coleta de } \\
\text { medidas antropométricas para } \\
\text { moda }\end{array}$ \\
\hline
\end{tabular}




\begin{tabular}{|c|c|c|}
\hline & $\begin{array}{l}\text { tamanho real dos modelos definidos, graduação dos moldes } \\
\text { ou coleta e desenvolvimento de modelagem sob medida. }\end{array}$ & $\begin{array}{l}{ }^{*} \text { Testar bases. Modelagem em } \\
\text { papel, Moulage, CAD. }\end{array}$ \\
\hline 14-Corte & Corte do tecido com a sobreposição dos moldes. & \\
\hline $\begin{array}{l}15 \text {-Costura do } \\
\text { protótipo }\end{array}$ & Costura das partes das roupas e realização dos acabamentos. & \\
\hline $\begin{array}{l}\text { 16-Aprovar ou } \\
\text { alterar o } \\
\text { tamanho do } \\
\text { protótipo e } \\
\text { estilo }\end{array}$ & $\begin{array}{l}\text { Discutir com os participantes os protótipos desenvolvidos, } \\
\text { checar as medidas e o estilo, se necessário realizar as devidas } \\
\text { correções. }\end{array}$ & $\begin{array}{l}{ }^{*} \text { Checklist de aprovação do } \\
\text { modelo }\end{array}$ \\
\hline $\begin{array}{l}\text { 17-Avaliação de } \\
\text { usabilidade e } \\
\text { ergonômica }\end{array}$ & $\begin{array}{l}\text { Avaliar a eficiência, eficácia e satisfação com a roupa por } \\
\text { meio do uso, fazendo com que o usuário se vista e dispa, e se } \\
\text { necessário realizar avaliação com cada parte da roupa para } \\
\text { aferir a funcionalidade no produto. Verificar a adaptação do } \\
\text { produto ao usuário, em se tratando da antropometria, pegas, } \\
\text { aviamentos e outros detalhes da interação usuário-produto. }\end{array}$ & $\begin{array}{l}\text { *Protocolo de avaliação da } \\
\text { usabilidade e ergonomia do } \\
\text { vestuário }\end{array}$ \\
\hline $\begin{array}{l}\text { 18-Alterações } \\
\text { no produto ou } \\
\text { aprovação }\end{array}$ & $\begin{array}{l}\text { Se necessário realizar alterações no protótipo/ produto para } \\
\text { que preencha os requisitos anteriormente coletados. }\end{array}$ & \\
\hline
\end{tabular}

Fonte: Das autoras, 2018.

\section{Conclusão}

Na literatura verificou-se a existência de sistematizações para cocriação, para cocriação de produtos de moda, bem como para o desenvolvimento de moda no geral, e para produtos de tecnologia assistiva. Contudo um método que apresente a cocriação para o desenvolvimento de moda focado em pessoas com deficiência não foi encontrado, e foi neste sentido que que foi desenvolvido este artigo.

A cocriação é apresentada para muitas áreas, e percebe-se uma distinção grande daquela voltada para interfaces digitais e de outro segmento voltado para produtos, e neste último contexto escolheu-se como referência Sanders e Stappers (2014) e seu processo de cocriação. Os trabalhos que apontam métodos de desenvolvimento de produtos de moda são variados, apresentou-se um método amplamente conhecido e utilizado, tanto para o ensino quanto para aplicação nas empresas de moda, o de Burns, Mullet e Bryant (2011).

Foram encontrados poucos métodos que abordam o desenvolvimento de produtos para pessoas com deficiência, portanto apresentou-se o Método para o Desenvolvimento de Recursos de Tecnologia Assistiva Baseado no Ergodesign, desenvolvido por Maia e Freitas (2014), e o Design with People apresentado pelo Conselho de Design da Noruega (2010). O primeiro é mais detalhado que o segundo em suas etapas, mas ambos abordam o desenvolvimento de produtos de maneira bem completa. Além dos métodos citados neste artigo os autores encontraram e estudaram muitos outros que estão disponíveis na literatura, e que não são aqui citados visto que o objetivo principal do artigo não é apresentar a revisão bibliográfica na íntegra, mas sim o método desenvolvido a partir dela.

Todos os métodos analisados concordam em uma fase inicial onde são coletados dados dos usuários, uma segunda fase de desenvolvimento do design, e uma terceira fase de prototipação e avaliação. Estas três fases compõe o Método de Cocriação de Moda Funcional para Pessoas com Deficiência com os nomes de Pré-design, Geração, e Prototipagem e Avaliação, a configuração do 
método pode ser vista na figura 3 e seu detalhamento está descrito no quadro 2 .

Como sugestão para futuros trabalhos indica-se a descrição detalhada das ferramentas citadas no quadro 3 e a posterior aplicação do método com designers, pessoas com deficiência, cuidadores e demais profissionais da saúde interessados no desenvolvimento de roupas funcionais para pessoas com deficiência.

\section{Referências}

ASSISTIVE TECHNOLOGY ACT. 29 U.S.C. § 3001. 1998.

BRASIL, 2004. Decreto № 5.296 de 2 ed dezembro.

(http://www.planalto.gov.br/ccivil_03/_ato2004-2006/2004/decreto/d5296.htm)

BROGIN, B.; OKIMOTO, M. L.; MARTINO, C. Modularity and Variety in the Customization of Functional Clothes for People with Disabilities. In: REBELO, F.; SOARES, M. (Org.). Advances in Ergonomics in Design. $1^{\circ}$ ed. Berlim: Springer, v. 588, 2017, p. 569-580.

BROGIN, B; OKIMOTO, M. L. Functional fashion and co-creation for people with disabilities. $20^{\circ}$ International Ergonomics Associations. Florença- Itália. 26-30 ago. 2018.

BURNS, L. D.; MULLET, K.K.; BRYANT, N. O. The business of fashion: Designing, manufacturing, and marketing. $2^{\circ}$ ed. New York, NY: Fairchild Publications. 2011.

CONFORTO, E. D.; AMARAL, D. C.; SILVA, S.L. Roteiro para revisão bibliográfica sistemática: aplicação no desenvolvimento de produtos e gerenciamento de projetos. In: Congresso Brasileiro de Gestão de Desenvolvimento de Produto, $8^{\circ}$, Porto Alegre, 2011. Anais do $8^{\circ}$ Congresso Brasileiro de Gestão de Desenvolvimento de Produto. Porto Alegre, 2011. p.12.

CONSELHO DE DESIGN DA NORUEGA. Innovating with people: the business of inclusive design. Noruega: Norsk Designrad, 2010.

DICIONÁRIO DE CAMBRIDGE. Sondas. 2018. Disponível em:

<https://dictionary.cambridge.org/pt/dicionario/ingles/probe>. Acesso em 18 jun. 2018.

GIL, A. C. Como elaborar projetos de pesquisa. $4^{\circ}$ ed. São Paulo: Atlas. 2002.

GUPTA, D. Functional Clonthing: Definition and Classification. Indian Journal of Fiber and Textile Research, v.36, p.321-326, dez. 2011.

HUR, E. S.; BEVERLEY, K. J. The role of craft in co-design system for sustainable fashion. In: Making Futures: the crafts as change maker in sustainably aware cultures, $2^{\circ}$, Dartington Estate, Devon, UK, 2013. Anais do Making Futures: the crafts as change maker in sustainably aware cultures. Dartington Estate, Devon, Reino Unido: Phymount College of Art, 2013, p.40-54.

HUR, E.; BEVERLEY, K.; CASSIDY, T. Development of An Ideation Toolkit Supporting Sustainable Fashion Design and Consumption. Research Journal of Textile and Apparel, vol. 17, $n^{\circ} 2$, p. 89 100, 2013.

HUSSAIN, S.; SANDERS, E. B.-N. Fusion of horizons: Co-designing with Cambodian children who have prosthetic legs, using generative design tools. CoDesign, Reino Unido, vol. 8, $n^{\circ} 1$, p. 43-79, 2012. 
IBGE - Instituto Brasileiro de Geografia e Estatística. Censo Demográfico 2010: Características gerais da população, religião e pessoas com deficiência. São Paulo: IBGE, 2010.

IDEO. Kit de ferramentas. $2^{\circ}$ ed. Versão em português. 2013. (https://hcd-connectproduction.s3.amazonaws.com/toolkit/en/portuguese_download/ideo_hcd_toolkit _complete_portuguese.pdf)

MAIA, F. N.; FREITAS, S. F. Proposta de um fluxograma para o processo de desenvolvimento de produtos de tecnologia assistiva. Caderno de Terapia Ocupacional. São Carlos: UFSCAR, v. 22, n . 3, p. 561-567, 2014.

MARTINS, S. B. O conforto no vestuário: uma interpretação da ergonomia: metodologia de avaliação de usabilidade e conforto no vestuário. Florianópolis, 2005. 140 p. Tese de Doutorado apresentada no Programa de Pós-Graduação em Engenharia de Produção da Universidade Federal de Santa Catarina. Florianópolis, 2005.

MERCUR. Diversidade na rua. Santa Cruz do Sul, RS. 2016.

OKIMOTO, M. L. Projeto RPDTA. Edital PGPTA n 59/2014. Anexo II - Roteiro Básico do Projeto. Universidade Federal do Paraná, Curitiba - PR. Projeto de 2015 a 2018.

OMS (Organização Mundial da Saúde). Relatório Mundial sobre a Deficiência. São Paulo: Governo do estado de SP, 2011.

PAZMINO, A. V. Como Se Cria - 40 Métodos Para Design De Produto. São Paulo: Edgard Bucher. 2015.

PIQUERAS, P. A research to design clothes based on anthropometric and usability needs of wheelchair users. In: European Congress on Innovation on Textiles for Health Care, Gent- Bélgica, 10 a11 out. 2013. Anais do European Congress on Innovation on Textiles for Health Care. GentBélgica, 2013. p.1-23.

SANDERS, E. B. Scaffolds for Building Everyday Creativity. In: Frascara, J. (ed.). Design for Effective Communications: Creating Contexts for Clarity and Meaning. New York, NY: Allworth Press. 2006.

SANDERS, E. B.-N.; STAPPERS, P. J. Probes, toolkits and prototypes: three approaches to making in codesigning. CoDesign, Reino Unido, v. 10, $n^{\circ} .1$, p. 5-14, 2014.

SPINUZZI, C. The methodology of participatory design. Applied Theory, v. 52, $n^{\circ}$. 2, p. 163-174, 2005.

TREPTOW, D. Inventando Moda: Planejamento de coleção. 5 ed. São Paulo: Doris Elisa Treptow. 2013.

WHITHERS, J. W. 0 impacto de um procedimento de dança hip hop na qualidade de vida e na participação social de crianças e adolescentes com paralisia cerebral. Dissertação (Mestrado) Programa de Pós-Graduação em Saúde da Criança e do Adolescente. Setor de Ciências da Saúde. Universidade Federal do Paraná. Curitiba. 2014.

YANG, J.; KINCADE, D. H.; CHEN-YU. J. H. Types of Apparel Mass Customization and Levels of Modularity and Variety: Application of the Theory of Inventive Problem Solving. Clothing and Textiles Research Journal, Estados Unidos, v. 33, n.3, p. 199-212, 2015. 